Conclusion Quantitative analysis of blood volume in aSAH provides a tool for prediction of cerebral vasospasm, DCI and clinical outcome that may have a higher performance and improved accuracy when compared to grading systems used in current practice.

Disclosures B. Daou: None. S. Khalsa: None. S. Anand: None. C. Williamson: None. K. Rajajee: None. K. Sheehan: None. A. Pandey: None.

\section{E-153 THE VALUE OF REPEATED DIGITAL SUBTRACTION ANGIOGRAPHY IN PATIENTS WITH INITIAL ANGIOGRAM-NEGATIVE PERIMESENCEPHALIC SUBARACHNOID HEMORRHAGE}

C Wipplinger*, C Preuss-Hernandez, M Fehn, J Klingenschmid, W Ho, A Goerke, C Thomé, 0 Petr. Department of Neurosurgery, Medical University of Innsbruck, Innsbruck, Austria

10.1136/neurintsurg-2020-SNIS. 185

Objective In approximately $15 \%$ of patients admitted with subarachnoid hemorrhage $(\mathrm{SAH})$ with a perimesencephalic blood distribution, digital subtraction angiography (DSA) fails to reveal a source of hemorrhage. These perimesencephalic non-aneurysmal hemorrhages usually have a benign clinical course and a significantly better prognosis than aneurysmal SAH. Recent studies hypothesized that repeated angiograms in this subset of patients does not add any valuable information. In the present study, we aimed to evaluate the value of repeated DSAs and complications in patients with perimesencephalic subarachnoid hemorrhage.

Methods We retrospectively reviewed the medical records of 73 patients with perimesencephalic subarachnoid hemorrhage and a negative initial angiogram admitted to our institution between 1998 and 2018. Findings of initial CT scans, DSAs as well as subsequent imaging including CT angiograms (CTA) and MR angiograms (MRA) were analyzed for significant findings as well as procedure-related complications.

Results All patients initially received a cranial CT scan followed by at least one DSA. In $41(56 \%)$ patients, DSA was repeated at least once and in $43(59 \%)$ patients a CTA was performed prior to the initial DSA. One patient (1.4\%) showed clinical deterioration and a recurrent hemorrhage on a follow-up CT scan. The subsequent DSA revealed a basilar artery dissection that was not identified on the initial DSA. Five $(6.8 \%)$ patients showed embolic strokes post DSA, requiring a decompressive suboccipital craniectomy in one (1.4\%) patient.

Conclusion In the majority of our patient population, repeated DSA did not add any clinically relevant information. However, if clinical deterioration with recurrent hemorrhage becomes apparent a repeated DSA may be indicated. Additionally, our findings show that DSA is an invasive procedure with potentially severe complications. Careful consideration is therefore necessary before indicating repeated DSAs.

Disclosures C. Wipplinger: None. C. Preuss-Hernandez: None. M. Fehn: None. J. Klingenschmid: None. W. Ho: None. A. Goerke: None. C. Thomé: None. O. Petr: None.

\section{E-154 INTERNAL CAROTID ARTERY INJURY DURING ENDOSCOPIC TRANSNASAL TRANSSPHENOIDAL SURGERY: A RETROSPECTIVE REVIEW}

G Wong*. Neurosurgery, The Chinese University of Hong Kong, Hong Kong, Hong kong

\subsection{6/neurintsurg-2020-SNIS. 186}

Introduction Internal carotid artery injury is a rare and severe intraoperative catastrophy. Endovascular treatment is the key to secure hemostasis. We aim to review our institutional results and learn from the experience.

Method We retrospectively reviewed all the patients undergoing neuro-endovascular intervention for the diagnosis of internal carotid artery injury during endoscopic transnasal transsphenoidal surgery between 2015 and 2019 in our institution.

Results We identified 4 patients with torrential intraoperative hemorrhage during endoscopic transnasal transphenoidal surgery requiring urgent catheter angiography. Three had diffuse subarachnoid hemorrhage and one had sole sellar hemorrhage. Diagnoses were pituitary marcoadenoma in 3 patients and mycosis in 1 patient. One aneurysm was embolized with coils and 2 patients were treated with main trunk occlusion together with the pseudoaneurysms. These 3 patients achieved favorable functional outcome upon discharge or after 
rehabilitation. One patient did not have angiographic crossflow was treated with flow diverters. The patient remained dependent and succumbed one year later.

Conclusion In patients with torrential intraoperative hemorrhage during endoscopic transnasal transphenoidal surgery, endovascular treatment is frequently required and hemostasis could be secured.

Disclosures G. Wong: None.

\section{E-155 HIGHER PREVALENCE OF INTRAPLAQUE HEMORRHAGE IN LEFT CAROTID ARTERIES THAN RIGHT}

${ }^{1} A$ Larson*, ' I Benson, 'G Lanzino, 'W Brinjikji. 'Neurosurgery, Mayo Clinic, Rochester, $M N{ }^{2}$ Radiology, Mayo Clinic, Rochester, MN

\subsection{6/neurintsurg-2020-SNIS. 187}

Background Ischemic stroke is more often diagnosed in the left hemisphere than the right. One prior study has found that there may be an asymmetrical prevalence of atherosclerosis with a higher prevalence of carotid artery disease on the left than the right.

Methods We sought to study the prevalence of carotid artery atherosclerosis and intraplaque hemorrhage in the right versus left carotid artery in a large population of patients.

Results Neck MRAs of 643 total patients were reviewed. Overall, there were similar degrees and distribution of degrees of stenosis. There was a higher prevalence of intraplaque hemorrhage in the left versus right carotid for all patients $(\mathrm{P}=0.02)$ and for symptomatic patients $(\mathrm{P}=0.002)$. This was not true for asymptomatic patients. There were no differences in the prevalence of plaque ulcer between right and left carotid arteries.

Conclusions In confirming a prior report, we found that left carotids are more likely to present with intraplaque hemorrhage as compared to right carotids. This was particularly true for patients with symptomatic manifestations including stroke, transient ischemic attack, amaurosis fugax and retinal artery occlusion. The reason underlying the increased prevalence of intraplaque hemorrhage in the left carotid artery remains enigmatic.

Disclosures A. Larson: None. J. Benson: None. G. Lanzino: None. W. Brinjikji: None.

\section{E-156 BRAINOMIX EASPECTS SOFTWARE IMPROVES INTEROBSERVER AGREEMENT AND ACCURACY OF NEUROLOGIST AND NEURORADIOLOGISTS IN INTERPRETATION OF ASPECTS SCORE AND OUTPERFORMS HUMAN READERS IN PREDICTION OF FINAL INFARCT}

${ }^{1}$ W Brinjikjit, , J Benson, ${ }^{1} \mathrm{~N}$ Campeau, ${ }^{1} \mathrm{C}$ Carr, ${ }^{1} \mathrm{P}$ Cogswell, ${ }^{2} \mathrm{~J}$ Klaas, ${ }^{1} \mathrm{G}$ Liebo, ${ }^{1} \mathrm{~J}$ Little, ${ }^{1} \mathrm{P}$ Luetmer, ${ }^{1} \mathrm{~S}$ Messina, ${ }^{1} \mathrm{~A}$ Nagelschneider, ${ }^{1} \mathrm{~K}$ Schwartz, ${ }^{1} \mathrm{C}$ Wood, ${ }^{1} \mathrm{D}$ Nasr, ${ }^{1} \mathrm{~S}$ Braksick, ${ }^{1} \mathrm{D}$ Kallmes. ${ }^{1}$ Radiology, Mayo Clinic, Rochester, MN; ${ }^{2}$ Neurology, Mayo Clinic, Rochester, $M N$

\subsection{6/neurintsurg-2020-SNIS.188}

Introduction There has been increased interest in the use of artificial intelligence based software packages in the evaluation of neuroimaging for patients with acute ischemic stroke. We performed an inter-rater agreement and accuracy study to determine if the use of the Brainomix eASPECTS software improved interobserver agreement and accuracy in detecting ASPECTS regions affected in anterior circulation LVO.

Methods We included 60 consecutive patients with anterior circulation LVO who had TICI 3 revascularization within 60 minutes of their baseline CT. A total of 16 readers; 6 senior neuroradiologists, 6 junior neuroradiologists and 4 vascular neurologists participated. Readers interpreted CT scans on an independent workstation and assessed final ASPECTS score and evaluated whether each individual ASPECTS region was affected. Two months later, the readers again evaluated the CT scans, but with the assistance of eASPECTS software. We assessed interclass correlation coefficient for total ASPECTS and interobserver agreement with Fleiss' Kappa for each ASPECTS region with and without assistance of the eASPECTS software. We also assessed accuracy for the readers with and without eASPECTS software assistance. In our assessment of accuracy, ground truth was the 24 hour CT in this cohort of patients who had prompt and complete revascularization as determined by two neuroradiologists.

Results Interclass correlation coefficient for total ASPECTS without eASPECTS assistance was 0.395 indicating fair agreement compared to 0.574 with eASPECTS assistance indicating good agreement $(\mathrm{P}<0.01)$. There was significant improvement in inter-rater agreement with eASPECTS assistance for each individual region with the exception of the M6 and caudate. For example, kappa statistics improved from 0.60 to 0.83 for the M1, 0.38 to 0.67 for the M2, 0.35 to 0.57 for the insula

\section{Abstract E-155 Table 1}

\begin{tabular}{|c|c|c|c|c|c|c|c|c|c|}
\hline & \multicolumn{3}{|l|}{ Overall } & \multicolumn{3}{|c|}{ Symptomatic Patients } & \multicolumn{3}{|c|}{ Asymptomatic Patients } \\
\hline & Right & Left & $\mathrm{P}$ & Right & Left & $P$ & Right & Left & $P$ \\
\hline $\mathrm{N}$ & 643 & 643 & - & 419 & 419 & - & 224 & 224 & - \\
\hline Mean (SD) Degree of Stenosis & $18.1(29.7)$ & $18.1(30.7)$ & 0.99 & $22.5(31.6)$ & $23.0(32.9)$ & 0.82 & $9.8(23.5)$ & $9.1(23.7)$ & 0.75 \\
\hline Plaque Ulcer N (\%) & $30(4.7)$ & $37(5.8)$ & 0.45 & $21(5.0)$ & $34(8.1)$ & 0.09 & $9(4.0)$ & $3(1.3)$ & 0.14 \\
\hline Plaque Hemorrhage N (\%) & $46(7.2)$ & $72(12.0)$ & 0.02 & $39(9.3)$ & $71(16.9)$ & 0.002 & $7(3.1)$ & $11(4.9)$ & 0.47 \\
\hline \multicolumn{10}{|l|}{ Degree of Stenosis N (\%) } \\
\hline$<30 \%$ & $469(72.9)$ & $475(73.8)$ & 0.75 & $278(66.3)$ & $279(66.6)$ & 0.99 & $191(85.2)$ & $196(87.5)$ & 0.58 \\
\hline $30-49 \%$ & $36(5.6)$ & $32(5.0)$ & 0.71 & $30(7.2)$ & $26(6.2)$ & 0.68 & $6(2.7)$ & $6(2.7)$ & 1.0 \\
\hline $50-69 \%$ & $64(10.0)$ & $59(9.2)$ & 0.71 & $52(12.4)$ & $51(12.2)$ & 0.99 & $12(5.4)$ & 8 (3.6) & 0.49 \\
\hline $70+\%$ & 74 (11.5) & 77 (12.0) & 0.86 & $59(14.1)$ & $63(15.0)$ & 0.77 & $15(6.7)$ & $14(6.3)$ & 0.99 \\
\hline
\end{tabular}

